\title{
A Single Center, Open-Labeled Trial To Investigate The Pharmacokinetics of Insulin Detemir in Healthy Taiwanese Subjects
}

\section{Ching Fai Kwok}

Division of Endocrinology and Metabolism, Department of Medicine, Taipei Veterans General Hospital and Cheng Hsin General Hospital., Taipei

\section{Low-Tone Ho ( $\boldsymbol{\sigma}$ LTHo@vghtpe.gov.tw )}

Department of Medical Education and Internal Medicine, Taipei Veterans General Hospital and School of Medicine, National Yang-Ming-Chao-Tung University School of Medicine, Taipei

\section{Research Article}

Keywords: investigate, Pharmacokinetics, insulin, NPH

Posted Date: October 18th, 2021

DOI: https://doi.org/10.21203/rs.3.rs-764757/v1

License: (a) (i) This work is licensed under a Creative Commons Attribution 4.0 International License. Read Full License 
A single center, open-labeled trial to investigate the Pharmacokinetics of insulin detemir in healthy Taiwanese subjects

Ching Fai Kwok, $\mathrm{MD}^{1}$, and Low Tone Ho, $\mathrm{MD}^{2}$.

${ }^{1}$ Division of Endocrine and Metabolism, Department of Medicine, Cheng Hsin General Hospital and Taipei Veterans General Hospital, Taipei, Taiwan.

${ }^{2}$ Department of Medical Education and Internal Medicine, Taipei Veterans General Hospital and School of Medicine, National Yang-Ming-Chao-Tung University School of Medicine, Taipei, Taiwan.

Correspondence:

Prof. Low-Tone Ho,

Department of Medical Education and Internal Medicine, Taipei Veterans General Hospital and National Yang-Ming-Chao-Tung University School of Medicine

Taipei, Taiwan, 112

Email: ltho@vghtpe.gov.tw

Grant support: this study is supported by research grant from Novo Nordisk, Taiwan 


\begin{abstract}
Backgrounds:

Insulin detemir(nn304) is a long-acting insulin analogue reported to provide more predictable blood glucose level throughout the day, leading to a lower within-subject variability compared to NPH insulin. Pharmacokinetic profiles of insulin detemir had not been investigated in Taiwanese. This study was to determine whether there is a difference between Taiwanese subjects in pharmacokinetic profile of insulin detemir compared to Caucasian subjects.
\end{abstract}

\title{
Methods:
}

Pharmacokinetic profile of insulin detemir was measured in twenty male Taiwaneses(nn304-3023). Eligible subjects were given insulin detemir as a single dose subcutaneous injection at $0.5 \mathrm{U} / \mathrm{kg}$ body weight in the mid-thigh using NovoPen ${ }^{\circledR} 3$ device. 32-hour serum insulin detemir concentrations were measured. Hypoglycemia and other adverse events were recorded. The results were compared to data obtained from a previous trial in Caucasian subjects (nn304-1451).

Results:

There was no significant difference between Taiwanese (nn304-3023) and Caucasian (nn304-1451) in the primary endpoint, $A \mathrm{AUC}_{(0-\infty)}$, and the secondary endpoints, $\mathrm{AUC}_{(0-24 h)}$, and $\mathrm{t}_{1 / 2}$. However, the secondary endpoints, Cmax was $40 \%$ higher, tmax was shorter(270.0 vs. $420.0 \mathrm{~min})$ and $\mathrm{AUC}_{(0-5 \mathrm{~h})}$ was 2-fold more in Taiwanese. When only male subjects were included in the comparator trial (nn3041451), the $t_{1 / 2}$ was significantly shorter in Taiwanese(348 min vs $404 \mathrm{~min}$ ). There was no significant difference in the mean blood glucose concentrations between Taiwanese and Caucasian subjects. A single episode of hypoglycemia(53 mg/dL) was reported in a 24-year-old male approximately 2.5 hours after the administration of insulin detemir. He was able to treat himself for the episode.

Conclusion:

In this pharmacokinetic evaluation of a single dose administration of insulin detemir in Taiwanese male subjects, the $\mathrm{AUC}_{(0-\infty)}$, and $\mathrm{AUC}_{(0-24 \mathrm{~h})}$ were not different from that of Caucasians in the comparator trial. However, insulin detemir appeared to be more rapidly absorbed in Taiwanese males. Further studies are warranted to elucidate its pharmacodynamic response and mechanisms. Finally, there was no clinically relevant safety concern raised in this study. (Funded by research grant from Novo Nordisk, Taiwan, first registration (22/12/2011) ClinicalTrials.gov number, NCT01497587

Introduction

Insulin detemir(NN304) is a derivative of human insulin $\left[\mathrm{Lys}^{\mathrm{B} 29}\left(\mathrm{~N}^{\mathrm{e}}\right.\right.$-tetradecanoyl) $\operatorname{des}\left({ }^{\mathrm{B} 30}\right)$ human insulin], in which the threonine residue at position B30 of the human insulin molecule has been removed and a C14 fatty acid side-chain has been attached to position B29. ${ }^{1}$ The fatty acid sidechain contributes to an increased self-association of hexamers, which delays hexamer dissociation and 
consequently absorption. ${ }^{2}$ Upon dissociation of the hexamers into dimers and monomers, the fatty acid residue associates with the free fatty acid binding sites on the albumin molecule in the interstitial fluid and in the plasma and prolongs the absorption of insulin detemir further. The free and biologically active fraction of insulin detemir permeates the capillary wall and enters the bloodstream, where it binds to albumin again. To reach the muscle and fat target tissues, insulin detemir dissociates from albumin and passes the capillary wall once more. Hence, the protracted action of insulin detemir is mediated by the strong self-association of insulin detemir molecules at the injection site and albumin binding (98-99\% bound to albumin in plasma ${ }^{2-4}$ via the fatty acid side-chain. The rate of absorption is slow due to the low concentration of insulin detemir available for diffusion through the tissue and passage across the capillary wall. In combination, the two mechanisms of protraction provide a more reproducible absorption and action profile of insulin detemir compared to NPH insulin. ${ }^{5}$ Insulin detemir is a clear and colourless solution, and provides a homogenous concentration of insulin detemir, which increases the dosing accuracy. The more reproducible action profile leads to a more predictable blood glucose level throughout the day, leading to a lower within-subject variability than that reported with $\mathrm{NPH}$ insulin. ${ }^{6}$ At equivalent dosing levels, insulin detemir has a longer duration of action than NPH insulin. No safety concerns have been raised during the preclinical and clinical phase 1, 2 and 3 trials. Clinical trials have confirmed a delayed but sustained blood glucose lowering effect with insulin detemir in both healthy subjects, and subjects with type 1 and type 2 diabetes. To date, clinical trials with insulin detemir in healthy subjects as well as in subjects with type 1 and type 2 diabetes have been conducted in Europe, USA, Japan and Australia. The latest results from clinical phase 3 trials have suggested that subjects with type 1 and 2 diabetes can be successfully treated with insulin detemir once or twice daily to cover basal insulin needs in combination with human soluble insulin or the rapid-acting insulin analogue administered at meals. ${ }^{5,6}$

The purpose of this study was to determine whether there was a difference between Taiwanese subjects in pharmacokinetic profile of insulin detemir compared to Caucasian subjects.

\section{Materials and Methods}

The trial design was based on trial NN304-1451 in order to compare with the Caucasian subjects in that trial ${ }^{7}$. Twenty Taiwanese male subjects were included based on the inclusion and exclusion criteria. The inclusion criteria were: healthy male Taiwanese subjects aged between 18 and 55 years (inclusive), body mass index (BMI) between 18 and $27 \mathrm{~kg} / \mathrm{m} 2$ (inclusive); fasting plasma glucose $\leq 6.1 \mathrm{mmol} / \mathrm{L}$ and non-smoker or smoking $\leq 5$ cigarettes per day or the equivalent. Exclusion criteria were: participation in any other clinical trial involving other investigational products within 
the last 3 months, previous participation in this trial, clinically significant abnormal hematology or biochemistry screening tests, any serious systemic infectious disease that occurred during the four weeks prior to the first dose of test drug, any intercurrent illness that may affect blood glucose, subject with a history of alcohol or drug dependence, any positive reaction of drug of abuse or alcohol screen, positive Hepatitis B or C or HIV screens, use of prescription drugs within 3 weeks preceding the first dosing of insulin detemir, mental incapacity, unwillingness or language barriers precluding adequate understanding or cooperation, subject with a first-degree relative with diabetes mellitus, history of, or presence of diabetes, cancer or any clinically significant cardiac, respiratory, metabolic, renal, hepatic, gastrointestinal, endocrinological, dermatological, venereal, hematological, neurological, or psychiatric disease or disorder as judged by the investigator, previous history of anaphylactic reaction, known or suspected allergy to trial product or related products.

An overview of the trial flow is provided in figure 1. The procedures for the relevant visit were conducted according to the trial flow chart. Before screening, subjects received a screening number in ascending order and were asked to attend the screening visit in a fasting state, having consumed only water since midnight. Blood samples were collected for the analysis of virology, hematology and clinical chemistry. Subjects were advised to abstain from strenuous activity $48 \mathrm{~h}$ prior to visit 1.

On visit 2, subjects were admitted to the Clinical Research Centre of Taipei Veterans General Hospital approximately at $1900 \mathrm{~h}$ in the evening of Day -1 and stayed until 32 hours after the subcutaneous dose. All subjects were given a carbohydrate-rich meal between $20 \mathrm{~h}$ and $22 \mathrm{~h}$ in the evening of Day -1. In the morning of Day 0, Insulin detemir was administered subcutaneously in the thigh region at time-point zero, using a NovoPen ${ }^{\circledR} 3$ device at a dose of $0.5 \mathrm{U} / \mathrm{kg}$ body weight. Serial blood sampling for the assessment of insulin detemir concentrations were performed at 30-minute intervals for 6 hours and then at 1-h intervals until $32 \mathrm{~h}$ post-dosing. A cannula was inserted antegradely into a vein for blood sampling. The cannula was kept open and free from coagulated blood by using a heparinized saline flush post sampling. One $\mathrm{mL}$ of blood was drawn and discarded. Thereafter, $4 \mathrm{~mL}$ of blood was drawn and $3.5 \mathrm{~mL}$ of blood was handled according to the laboratory manual from Capio Diagnostik. The remaining $0.5 \mathrm{~mL}$ of blood was taken for bedside glucose measurement using a glucometer. The total amount of blood drawn for this trial did not exceed 120 mL per subject. Insulin detemir concentration was measured by Capio Diagnostik Clinical Trials Lab, Copenhagen using the insulin detemir-specific enzyme-linked immunosorbent assay.

Subjects were required to remain in a supine or semi-supine position for at least 6h after the administration of the trial product. Thereafter, they were allowed to walk around. Meals were served at 30 minutes prior to dose administration, and approximately 3, 22, and 26 hours post dosing. Snacks were given on 5 and 7 hours post dosing. 
Adverse events ${ }^{8}$ included hypoglycemia and any other undesirable medical event occurring to the subject, whether or not related to trial product. The subjects were asked at each contact with the site if they had had any adverse events. All adverse events were recorded by the investigator and evaluated.

The protocol was approved by the independent Ethics Committee of Taipei Veterans General Hospital prior to study initiation. The study was performed in accordance with the Declaration of Helsinki(1964) ${ }^{9}$ and the local Good Clinical Practice regulations. Informed consent was obtained in writing prior to any study-related activities.

Statistical methods: statistical analysis was performed using SAS version 8.2 on a Microsoft Windows platform and pharmacokinetic parameters were calculated. ${ }^{10}$ The primary endpoint was the area under the insulin detemir concentration curve from zero to infinity $\left(\operatorname{AUC}_{(0-x)}\right)$. The null hypothesis was that there was no difference in $\left(\mathrm{AUC}_{(0-\infty)}\right)$ in Taiwanese subjects compared to Caucasian subjects in trial nn304-1451 with thigh administration of insulin detemir. The logtransformed primary endpoint, $\left(\mathrm{AUC}_{(0-\infty)}\right)$ was analyzed using an ANOVA model with ethnic group as fixed effect. The ratio of the geometric means for the two ethnic groups was obtained, together with the 95\% confidence interval (CI). The secondary endpoints were the maximum insulin detemir concentration $\left(\mathrm{C}_{\max }\right)$, time to maximum insulin detemir concentration $\left(\mathrm{t}_{\max }\right)$, mean residence time of insulin detemir(MRT), the area under the insulin detemir concentration curve in the time interval 0 $5 \mathrm{~h}\left(\mathrm{AUC}_{(0-5 \mathrm{~h})}\right)$, the area under the insulin detemir concentration curve in the time interval 0 24h(AUC $(0-24 h)$, and insulin detemir half-life $\left(\mathrm{t}_{1 / 2}\right)$. The safety endpoints were: incidence of hypoglycemic episodes, adverse events and serious adverse events, laboratory assessments, weight, vital signs and physical examination. All summary tables described for hypoglycemia and adverse events were based on treatment emergent events only, that is, events starting after the time of first administration of the trial product and within 7 days after the last treatment day.

Subjects were excluded from the analysis if they did not fulfill any of inclusion or exclusion criteria, or had any protocol violation such that the assessment of pharmacokinetic endpoints was likely to be biased or had unacceptable data quality. For comparison, data from Caucasian subjects in a previously published trial nn304- $1451^{7}$ were used. A significance level of 5\% was used throughout the analyses, unless stated otherwise.

Results

Twenty Taiwanese subjects completed the study. Their demographic data were shown in table 1. Two of them were excluded from the pharmacokinetic analysis due to violation of protocol. There 
was no significant difference between Taiwanese and Caucasian in the primary endpoint, AUC $_{(0-\infty)}$. The ratio was 0.9 (95\% CI: 0.83; 1.07, p=0.327). (table 2)

For the secondary endpoints, there was no significant difference between Taiwanese and Caucasian in the $\mathrm{AUC}_{(0-24 h)}$ and $\mathrm{t}_{1 / 2}$ (table 2, figure 2). However, the $\mathrm{C}_{\max }$ was $40 \%$ higher (ratio was 1.4, 9\% CI 1.19;1.60, $\mathrm{p}<0.0001$ ) and $\mathrm{AUC}_{(0-5 \mathrm{~h})}$ was doubled (ratio was 2, 95\% CI 1.56; 2.62, $\mathrm{p}<0.0001$ )in Taiwanese compared to Caucasians (table 2, figure 2). Furthermore, the $\mathrm{t}_{\max }(270.0$ vs. 420.0 min, $\mathrm{p}=0.0005$ ) and MRT (ratio was 0.7, 95\% CI: 0.62;0.76, $\mathrm{p}<0.0001$ ) were significantly shorter in Taiwanese. (table 2, figure 2).

As Taiwanese subjects were lighter in weight and only male subjects were included, we decided to explore if the results of pharmacokinetic analysis could have been influenced by factors such as BMI and gender. Exploratory analysis was carried out by including BMI as a covariate in the ANOVA model. The results were similar to the analysis without any adjustments for BMI(data not shown). Hence, BMI was not found to be a confounding factor on pharmacokinetic endpoints. When only male subjects were included in the comparator trial (NN304-1451) ${ }^{7}$, the results showed no significant difference between Taiwanese and Caucasian in the primary endpoint, $\mathrm{AUC}_{(0-\infty)}$ with a ratio of $0.9(95 \% \mathrm{CI}: 0.75 ; 1.01, \mathrm{p}=0.062)$. For the secondary endpoints, there was no significant difference between Taiwanese and Caucasian in the $\mathrm{AUC}_{(0-24 \mathrm{~h})}$, with a ratio of $1(95 \% \mathrm{CI}$ : 0.82;1.12, $\mathrm{p}=0.587)$. But the $\mathrm{t}_{1 / 2}$ was significantly shorter with a ratio of 0.9 (95\% CI: $\left.0.76 ; 0.97, \mathrm{p}=0.016\right)$. The $\mathrm{C}_{\max }$ was $50 \%$ higher(ratio was 1.5, 95\% CI: 1.28; 1.81, $\left.\mathrm{p}<0.0001\right)$ and $\mathrm{AUC}_{(0-5 \mathrm{~h})}$ was 1.5 -fold more(ratio was 2.5, 95\% CI: 2.02; 3.16, $\mathrm{p}<0.0001$ ) in Taiwanese compared to Caucasians. Furthermore, $\mathrm{t}_{\max }(270.0$ vs. $420.0 \mathrm{~min}, \mathrm{p}=0.0005$ ) and MRT (ratio was 0.7, 95\% CI: 0.62;0.76) were significantly shorter in Taiwanese subjects.

The mean blood glucose concentration is shown in figure 3. Over 32h, there was no significant difference in the mean blood glucose concentrations between Taiwanese and Caucasian subjects.

Adverse Events: only two non-serious events were reported by two subjects, both of which were mild in severity and assessed as unlikely to be related to administration of trial product. A single episode of hypoglycemia was reported in a 24-year-old male, reported experiencing symptoms of hypoglycemia approximately $2.5 \mathrm{~h}$ after the administration of insulin detemir. Blood glucose level was $53 \mathrm{mg} / \mathrm{dL}$ and he was able to treat himself for the episode.

\section{Discussion}

In the present study, the pharmacokinetic profile of insulin detemir after a single dose administration to the thigh in healthy male Taiwanese subjects was compared to healthy male/female 
Caucasian subjects in an earlier similar study (nn304-1451) ${ }^{7}$. Except for gender the inclusion criteria were similar in both trials with regard to age, range and BMI. The demography showed that Taiwanese subjects were younger (23.8 \pm 4.2 vs. $32.6 \pm 9.9$ years) than Caucasians and had lower BMI (21.9 \pm 1.9 vs. $24.1 \pm 1.9 \mathrm{~kg} / \mathrm{m} 2)$. Equal gender distribution was observed among the Caucasian subjects. The dose of insulin detemir $(0.5 \mathrm{U} / \mathrm{kg})$ administered to Taiwanese was equivalent to the dose (12 nmol/L) administered to Caucasian. Due to their lower body weight, Taiwanese subjects received a lower total dose of insulin detemir than Caucasians (32.6 U vs. $36.8 \mathrm{U}$ ). There were no apparent differences between Taiwanese and Caucasian with regard to physical examination, concomitant illnesses/medication or medical history.

Although we found no difference between Taiwanese and Caucasian in the $\mathrm{AUC}_{(0-\infty)}, \mathrm{AUC}_{(0-}$ 24h) and $t_{1 / 2}$, there was a left shift of in the curve for serum concentration of insulin detemir(figure 2) suggesting a faster absorption of the insulin detemir in Taiwanese male subjects. This hypothesis is further supported by the finding of a significantly shorter $t_{1 / 2}$ in Taiwanese when the comparison was done between Taiwanese and Caucasian including male-only. The observation of comparable $t_{1 / 2}$ compared to Caucasian in the main analysis was possibly confounded by female gender. Although the mean blood glucose levels showed no difference between Taiwanese and Caucasian subjects, the consequence of the left shift for insulin detemir concentration was not clear since it was not investigated in this study. Further study with the effects of meals and endogenous insulin secretion controlled involving techniques such as glucose clamp may be needed.

The action of insulin detemir is reported to be prolonged by association of the fatty acid residue to binding sites on albumin in the subcutaneous extracellular fluid and blood. ${ }^{11,12}$ With more than $98 \%$ of insulin detemir bound to albumin, the rate of absorption is limited by the low concentration of available insulin detemir for diffusion. In comparing anthropometric measurements between Asians and Caucasians, Wang et al ${ }^{13}$ found that fat for the same BMI category Asians have higher \% body fat and thicker subcutaneous fat, except for the thigh. The skin fold fat area of the midthigh in Caucasian males tended to be thicker than Asian males. It could be hypothesized that the lower mid-thigh subcutaneous space of Taiwanese may result in more rapidly diffusion of insulin detemir molecule than in Caucasian in the first $5 \mathrm{~h}$ after subcutaneous injection into the thigh.

Ethnic differences in the pharmacokinetics of insulin detemir had been explored and found to be similar between healthy Japanese American and Caucasian subjects. ${ }^{14}$ However, we are unable to make comparison with that of healthy Japanese ${ }^{14}$ due to different dosages used in this study.

The limitation of this study was that healthy Caucasian male subjects were not recruited at the same period and put through similar protocols under the same conditions as healthy Taiwanese male 
subjects. Although we did observe consistently higher mean blood glucose concentrations in Taiwanese than Caucasian subjects regardless of insulin detemir concentration, (figure 3) the pharmacodynamic effect of insulin detemir cannot be inferred because several factors could have influenced the blood glucose concentration curve. For example, the glycemic index and the calorie count of the carbohydrate-rich meal served in both trials may not be similar. As no baseline 24h blood glucose values were collected in this trial, any inference on the blood glucose lowering effect of insulin detemir is inconclusive based on the results of this trial. Including pharmacodynamic response would enable us to determine if the difference in pharmacokinetic profiles between the two ethnic groups will translate into significant differences in pharmacodynamic endpoints.

In conclusion, in this pharmacokinetic evaluation of a single dose administration of insulin detemir in Taiwanese male subjects, the $\mathrm{AUC}_{(0-\infty)}$, and $\mathrm{AUC}_{(0-24 \mathrm{~h})}$ were not different from that of Caucasians in the comparator trial. However, insulin detemir appeared to be more rapidly absorbed in Taiwanese males. Further studies are warranted to elucidate its pharmacodynamic response and mechanisms. Finally, there was no clinically relevant safety concern raised in this study. (Funded by research grant from Novo Nordisk, Taiwan, first registration (22/12/2011) ClinicalTrials.gov number, NCT01497587.

\section{Declaration}

Ethics approval and consent to participate:

The protocol, the protocol amendments, the consent form, and the subject information sheet were reviewed and approved by an independent Ethics Committee, Taipei Veterans General Hospital and submitted to the appropriate health authority, according to local regulations prior to trial initiation. The approval date was 19/04/2005(NN304-3203). The trial was performed in accordance with the "Declaration of Helsinki" and local Good Clinical Practice regulations. The subjects were informed of the risks and benefits of the trial and that they could withdraw from the trial at any time for any reason. Consent was obtained in writing prior to any trial-related activities and the Investigators retained the consent forms; the consent forms were available to Novo Nordisk for inspection.

Consent for publication

Not applicable.

Availability of data and materials

All data generated or analysed during this study are included in this published article.. Funding

Funded by research grant from Novo Nordisk, Taiwan, 19/04/2005,NN304-3203; Authors' contribution

C.F.K. wrote the manuscript. All authors reviewed the manuscript. 


\section{Acknowledgements}

We thank the staff of GCRC of Taipei Veterans General Hospital for their support for this study.

\section{Competing interests}

The authors declare that they have no competing interests.

Authors' information

NA

\section{Footnotes}

NA

\section{References}

1. Kurtzhals P, Havelund S, Jonassen I, Kiehr B, Larsen UD, Ribel U, Markussen J. Albumin binding of insulins acylated with fatty acids: characterizations of the ligand-protein interaction and correlation between binding affinity and timing of the insulin effect in vivo. Biochem J 1995; 312: 725-31.

2. Whittingham JL, Havelund S, Jonassen I. Crystal structure of a prolonged-acting insulin with albumin binding properties. Biochemistry 1997; 36: 2826-31.

3. Markussen J, Havelund S, Kurtzhals P, Andersen AS, Halstrom J, Hasselager E, Larsen UD, Ribel U, Schaffer L, Vad K, Jonassen I. Diabetologia 1996; 39: 281-8.

4. Jehle PM, Micheler C, Jehle DR, Breitig D, Boehm BO. Inadequate suspension of neutral protamine Hagedorn (NPH) insulin in pens. Lancet 1999; 354: 1604-7.

5. Vague P, Selam JL, Skeie S, De Leeuw I, Elite JWF, Haahr H, Kristensen A, Draeger E. Insulin detemir is associated with more predictable glycemic control and reduced risk of hypoglycemia than $\mathrm{NPH}$ insulin in patients in type 1 diabetes on a basal-bolus regimen with premeal insulin aspart. Diabetes Care 2003; 26: 590-6.

6. Haak T, Tiengo A, Waldhaus W, Draeger E. Treatment with insulin detemir is associated with predictable fasting blood glucose levels and favorable weight development in subjects with type 2 diabetes. Diabetes 2003; 52 (Suppl 1): A120.

7. Internal Novo Nordisk A/S Clinical Trial Report, NN304-1451. An open, randomized, cross-over trial in healthy subjects comparing the pharmacokinetics of insulin detemir when administered subcutaneously at different injection sites (abdomen, thigh, deltoid) investigating the absolute bioavailability.

8. Vague P, Selam J-L, Skeie S. et al. Insulin detemir is associated with more predictable glycemic control and reduced risk of hypoglycemia than NPH insulin in patients with type 1 diabetes on a basal-bolus regimen with premeal insulin aspart. Diabetes Care 2003; 26:590-596. 
9. Declaration of Helsinki. Recommendations guiding medical physicians in biomedical research involving human subjects. JAMA 1997; 277 (11): 925-926.

10. Leon Shargel and Andrew BC Yu: Statistics. In Appendix A, Applied Biopharmaceutics and Pharmacokinetics, 4th edition. McGraw-Hill Medical Publishing Division; 1999:643-652.

11. Kurtzhals P, Havelund S, Jonassen I, Ribel U, Markussen J. Mode of action of fatty acid acylated insulin: a novel type of soluble, long-acting insulin analogues. Diabetes 1996; 45: 222A.

12. Markussen J, Havelund S, Kurtzhals P, Andersen AS, Halstrom J, Hasselager E, et al. Soluble, fatty acid acylated insulins bind to albumin and show protracted action in pigs. Diabetologia 1996; 39: 281-8.

13. Wang J, Thornton JC, Russell M, Burastero S, Heymsfield S, Pierson RN. Asians have lower body mass index (BMI) but higher percent body fat than do whites: comparisons of anthropometric measurements. Am J Clin Nutr 1994; 60: 23-8.

14. Jhee SS, Lyness WH, Rojas PB, Leibowitz MT, Zarotsky V, Jacobsen LV. Similarity of insulin detemir pharmacokinetics, safety, and tolerability profiles in healthy Caucasian and Japanese American subjects. J Clin Pharmacol 2004; 44: 258-64.

Figure 1 overview of the trial flow

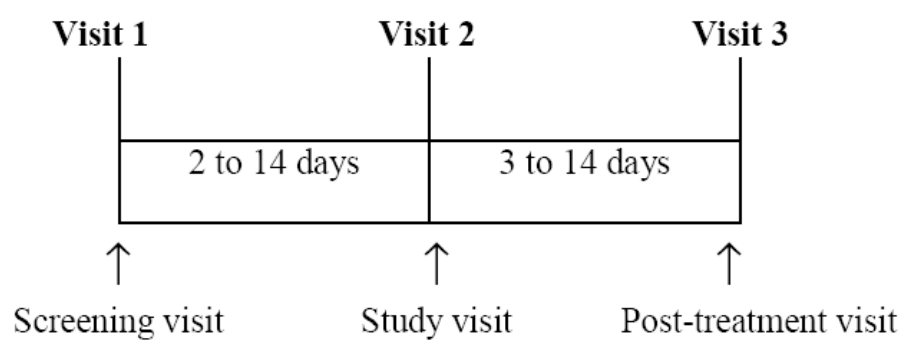


Figure 2:

Mean Insulin Detemir Concentration (pmol/L) over 32h in Taiwanese(3023) and Caucasians(1451) after a single injection of insulin detemir

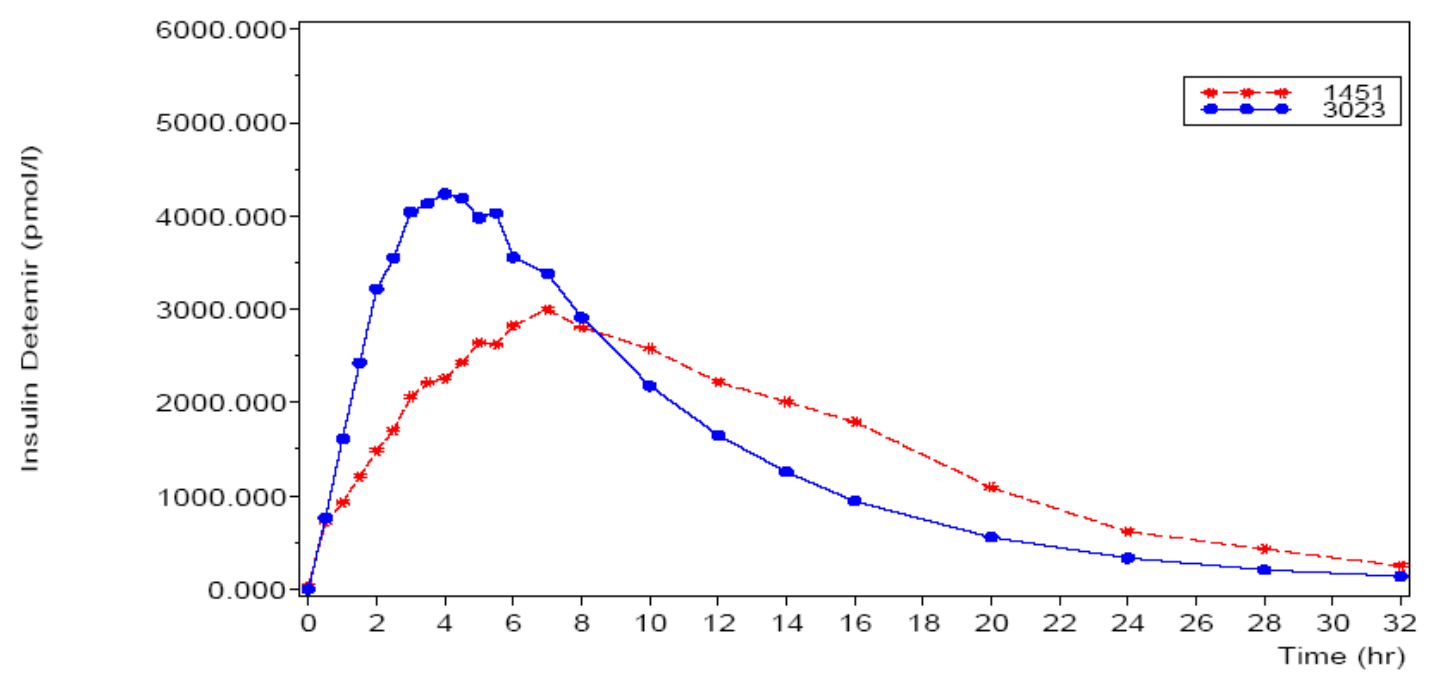

Figure 3:

Mean blood glucose concentrations over 32 hours in Taiwanese (3023) and Caucasians(1451) after a single injection of insulin detemir

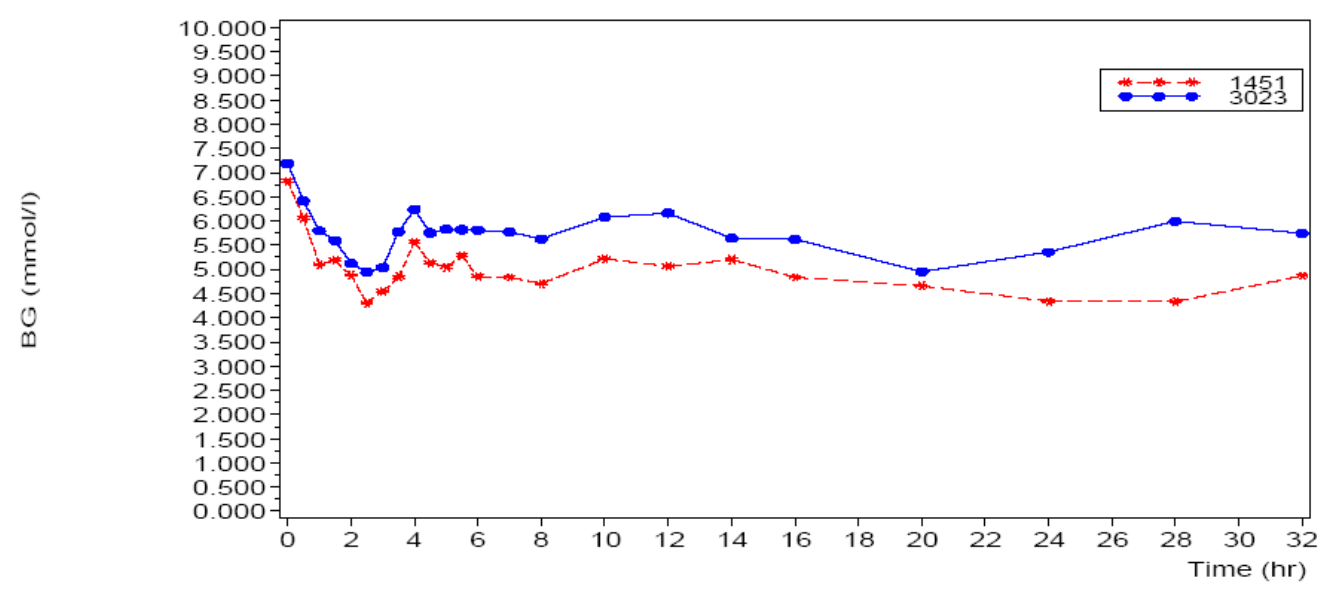


Table 1 Baseline demographic data in Taiwanese subjects(nn304-3023) and Caucasians(nn304-1451)

\begin{tabular}{|c|c|c|}
\hline & nn304-1451@ & nn304-3023 \\
\hline Number of Subjects Exposed & 28 & 20 \\
\hline $\begin{array}{l}\text { Age, years } \\
\text { N } \\
\text { Mean (SD) } \\
\text { Median } \\
\text { Min - Max }\end{array}$ & $\begin{array}{l}28 \\
32.6(9.9) \\
32.7 \\
18.3-51.4\end{array}$ & $\begin{array}{l}20 \\
23.8(4.2) \\
23.4 \\
19.2-36.6\end{array}$ \\
\hline $\begin{array}{c}\text { Sex, } N(\%) \\
\text { Female } \\
\text { Male }\end{array}$ & $\begin{array}{l}14(50.0 \%) \\
14(50.0 \%)\end{array}$ & $\begin{array}{ll}0 & (0.0 \%) \\
20 & (100 \%)\end{array}$ \\
\hline $\begin{array}{l}\text { Weight, kg } \\
\text { N } \\
\text { Mean (SD) } \\
\text { Median } \\
\text { Min - Max }\end{array}$ & $\begin{array}{l}28 \\
72.8(10.2) \\
70.0 \\
61.0-102.0\end{array}$ & $\begin{array}{l}18 \\
65.1(6.4) \\
63.7 \\
54.6-78.5\end{array}$ \\
\hline $\begin{array}{l}\text { Height, m } \\
\text { N } \\
\text { Mean (SD) } \\
\text { Median } \\
\text { Min - Max }\end{array}$ & $\begin{array}{l}28 \\
174(9.52) \\
173- \\
154-196\end{array}$ & $\begin{array}{l}18 \\
172(4.39) \\
172- \\
165-180\end{array}$ \\
\hline $\begin{array}{l}\text { BMI, } \mathrm{kg} / \mathrm{m} \wedge 2 \\
\text { Mean (SD) } \\
\text { Median } \\
\text { Min - Max }\end{array}$ & $\begin{array}{l}28 \\
24.1(1.9) \\
24.3 \\
19.8-27.0\end{array}$ & $\begin{array}{l}18 \\
21.9(1.9) \\
22.2 \\
18.7-25.9\end{array}$ \\
\hline
\end{tabular}


Table 2: Pharmacokinetic parameters in Taiwanese subjects(nn304-3023) compared to Caucasians(nn304-1451)

\begin{tabular}{|c|c|c|c|c|}
\hline & & nn304-1451@ & $\mathrm{nn304-3023}$ & $\begin{array}{l}3023 \text { vs } \\
14519^{\wedge}\end{array}$ \\
\hline \multicolumn{2}{|c|}{ Number of subjects } & 26 & 18 & \\
\hline \multicolumn{2}{|c|}{$\begin{array}{l}\text { AUC (O-inf), pmol/1*min } \\
\text { Mean (SD) } \\
\text { Median } \\
\text { Min - Max } \\
\text { Estimate } \\
95.0 \% \text { C.I. } \\
\text { p-value }\end{array}$} & $\begin{array}{l}2987516.0(545452.6) \\
2981314.44-3838962.2 \\
2050718.6-307.1 \\
2939007.1 \\
{[2710720.1 ; 3186519.7]}\end{array}$ & $\begin{array}{l}2831626.2(660003.3) \\
2763075.6-45025.7 \\
1836563.8-4250225.7 \\
2761852.0 \\
{[2506087.7 ; 3043718.8]}\end{array}$ & $\begin{array}{l}0.9 \\
{[0.83 ; 1.07]} \\
0.327\end{array}$ \\
\hline \multicolumn{2}{|c|}{$\begin{array}{l}\text { AUC }(0-5 h), \text { pmol } 1 / 1 * \text { min } \\
\text { Mean (SD) } \\
\text { Median } \\
\text { Min - Max } \\
\text { Estimate } \\
95.0 \% \text { C.I. } \\
\text { p-value }\end{array}$} & $\begin{array}{r}489814.6(219857.8) \\
458685.0 \\
126165.0-944475.0 \\
437269.7 \\
{[369946.0 ; 516845.1]}\end{array}$ & $\begin{array}{l}904128.3(191784.2) \\
906465.0 \\
524520.0-1264800.0 \\
883303.4 \\
{[722507.4 ; 1079885.0]}\end{array}$ & $\begin{array}{l}2.0 \\
{[1.56 ; 2.62]^{*}} \\
<0.0001^{*}\end{array}$ \\
\hline \multicolumn{2}{|c|}{$\begin{array}{l}\text { AUC }(0-24 \mathrm{~h}) \text {, pmol } / 1^{* m i n} \\
\text { Mean (SD) } \\
\text { Median } \\
\text { Min - Max } \\
\text { Estimate } \\
95.0 \% \mathrm{C} . \mathrm{I} . \\
\text { p-value }\end{array}$} & $\begin{array}{l}2639841.9(479433.7) \\
2626890.0 \\
1842300.0-3500325.0 \\
2597592.5 \\
{[2392600.9 ; 2820147.3]}\end{array}$ & $\begin{array}{l}2660035.0(640198.0) \\
2612805.0 \\
1707510.0-3931680.0 \\
2589531.7 \\
{[2345925.7 ; 2858434.3]}\end{array}$ & $\begin{array}{l}1.0 \\
{[0.88 ; 1.13]} \\
0.961\end{array}$ \\
\hline \multicolumn{2}{|c|}{$\begin{array}{l}\text { Cmax, pmo1/1 } \\
\text { Mean (SD) } \\
\text { Median } \\
\text { Min - Max } \\
\text { Estimate } \\
\text { 95.0\% C.I. } \\
\text { p-value }\end{array}$} & $\begin{array}{l}3577.3(861.3) \\
3735.0 \\
2000.0-5280.0 \\
3474.4 \\
{[3157.9 ; 3822.6]}\end{array}$ & $\begin{array}{r}4917.2(1122.0) \\
4785.0 \\
3020.0-7240.0 \\
4798.9 \\
{[4278.5 ; 5382.7]}\end{array}$ & $\begin{array}{l}1.4 \\
{[1.19 ; 1.60] *}\end{array}$ \\
\hline \multicolumn{3}{|c|}{$\begin{array}{ll}\text { Tmax, min } & \\
\text { Mean (SD) } & 443.1 \text { (213.4) } \\
\text { Median } & 420.0 \text { - } \\
\text { Min - Max } & 30.0-960.0 \\
\text { P-value, Kruskal Wa11is Test }\end{array}$} & $\begin{array}{l}275.0(75.1) \\
270.0- \\
180.0-420.0\end{array}$ & $0.0005^{*}$ \\
\hline \multicolumn{2}{|c|}{$\begin{array}{l}\text { T-ha1f, min } \\
\text { Mean (SD) } \\
\text { Median } \\
\text { Min - Max } \\
\text { Estimate } \\
95.0 \% \text { C.I. } \\
\text { p-value }\end{array}$} & $\begin{array}{r}366.4(68.4) \\
365.7 \\
253.9-518.9 \\
360.4 \\
{[336.2 ; 386.3]}\end{array}$ & $\begin{array}{l}348.2(52.8) \\
360.9 \\
259.0-407.4 \\
344.2 \\
{[316.7 ; 374.1]}\end{array}$ & $\begin{array}{l}1.0 \\
{[0.86 ; 1.06]} \\
0.398\end{array}$ \\
\hline \multicolumn{2}{|c|}{$\begin{array}{ll}\text { MRT, } & \text { min } \\
\text { Mean (SD) } \\
\text { Median } \\
\text { Min - Max } \\
\text { Estimate } \\
95.0 \% \text { C.I. } \\
\text { p-value }\end{array}$} & $\begin{array}{r}785.6(156.2) \\
794.0 \\
568.7-1149.5 \\
771.2 \\
{[722.4 ; 823.3]}\end{array}$ & $\begin{array}{l}577.0(72.2) \\
562.3 \\
414.6-722.2 \\
527.3-5 \\
{[487.5 ; 570.4]}\end{array}$ & $\begin{array}{l}0.7 \\
{[0.62 ; 0.76]^{*}} \\
<0.0001^{*}\end{array}$ \\
\hline
\end{tabular}

@Data for nn304-1451 is obtained from a previous study on Caucasian subjects.

Ratio of treatment estimates are presented (except Tmax).

A11 PK endpoints (except Tmax) are analysed by ANova model on log scale. 